\title{
Incidence of akathisia after PONV prophylaxis with droperidol or ondansetron in outpatient surgery. A multicenter controlled randomized trial
}

\author{
Charton A ${ }^{1}$, Ruimy $\mathbf{A}^{1}$, Greib N² , Faitot $\mathbf{V}^{1}$, Meyer $\mathbf{N}^{3}$, Diemunsch $\mathbf{P}^{1}$ \\ 1. Department of Anaesthesia and Intensive Care, Hôpital de Hautepierre, Strasbourg University Hospital, France \\ 2. Department of Anaesthesia, Clinique Rhena, Strasbourg, France \\ 3. GMRC, Public Health Service, Strasbourg University Hospital
}

\section{Background and Goal of study}

Droperidol is recommended for prevention of postoperative nausea and vomiting (PONV). In 19 of 24 European countries, droperidol is regularly used in this indication ${ }^{1}$. Akathisia is an extra-pyramidal symptom induced by dopamine antagonists, often identified as restlessness by anaesthesists. Akathisia is a very unpleasant and possibly harmful side-effect, which can lead to readmissions after ambulatory surgery. Even low doses of droperidol may induce akathisia ${ }^{1}$. The aim of this controlled randomized trial is to evaluate the incidence of akathisia after PONV prophylaxis with droperidol or ondansetron, in outpatient surgery.

0 Absent. No evidence of awareness of restlessness. Observation of characteristic movements of akathisia in the absence of a subjective report of inner restlessness or compulsive desire to move the legs should be classified as pseudoakathisia

1 Questionable. Non-specific inner tension and fidgety movements

2 Mild akathisia. Awareness of restlessness in the legs and/or inner restlessness worse when required to stand still. Fidgety movements present, but characteristic restless movements of akathisia not necessarily observed. Condition causes little or no distress.

3 Moderate akathisia. Awareness of restlessness as described for mild akathisia above, combined with characteristic restless movements such as rocking from foot to foot when standing. Patient finds the condition distressing

4 Marked akathisia. Subjective experience of restlessness includes a compulsive desire to walk or pace. However, the patient is able to remain seated for at least five minutes. The condition is obviously distressing.

5 Severe akathisia. The patient reports a strong compulsion to pace up and down most of the time. Unable to sit or lie down for more than a few minutes. Constant restlessness which is associated with intense distress and insomnia.

Global Clinical Assessment of Akathisia (Barnes Akathisia Rating Scale) ${ }^{2}$

\section{Material and Methods}

With local ethics committee approval 297 patients with an Apfel score $\geq 2$, scheduled to undergo ambulatory surgery under general anaesthesia, were randomized to receive iv PONV prophylaxis with droperidol $0.625 \mathrm{mg}$, or droperidol $1.25 \mathrm{mg}$ or ondansetron 4mg. After discharge from the recovery room (RR), the Barnes' rating $s^{2}{ }^{2}$ was used for the global clinical assessment of akathisia in each patient. Akathisa is defined by a Barnes score $\geq 2$ and severe or marked akathisia by a Barnes score $\geq 4$. The occurence of PONV was recorded in the RR and 4 hours after recovery from anaesthesia. Data were analysed using Bayesian methods. An effect is considered as significant if the probability that the effect exceeds a given threshold is larger than 0.95. Results are expressed as mean or rate and $95 \%$ credibility intervals.

\section{Results and Discussion}

There were no differences for the patients characteristics in the 3 groups. Higher number of women is due to the fact that the female sex is a risk factor in the Apfel score, which was an inclusion criteria. No differences were observed across the 2 droperidol groups. Incidence of akathisia was 4/171 in the droperidol groups (0.625 and $1.25 \mathrm{mg})$ and $1 / 121$ in the ondansetron group (Tab 1). The Bayesian estimates rates are $2.7 \%$ and $1.4 \%$ respectively and $\operatorname{Pr}($ Dro $>$ Ond $)=78.2 \%$. Taking account of prior data3, as possible in the Bayesian Paradigm, $\operatorname{Pr}($ Dro $>$ Ond $)=93.1 \%$. We observed one case of marked akathisa in the $1.25 \mathrm{mg}$ droperidol group. Using the Barnes' rating scale, we observed more objective signs of akathisia in the droperidol group than in the ondansetron group. The case of mild akathisia in the ondansetron group is explained by the presence of subjective criteria of distress. Incidence of PONV was low and comparable in the 3 groups.

\begin{tabular}{|c|c|c|c|}
\hline & $\begin{array}{l}\text { Droperidol } \\
0.625 \mathrm{mg}\end{array}$ & $\begin{array}{c}\text { Droperidol } \\
1.25 \mathrm{mg}\end{array}$ & $\begin{array}{c}\text { Ondansetron } \\
4 \mathrm{mg}\end{array}$ \\
\hline $\mathbf{N}$ & 87 & 89 & 121 \\
\hline Gender (male) & $19(21.8 \%)$ & 17 (19.1\%) & 32 (26.5\%) \\
\hline Age (year) & $\begin{array}{c}43.1 \\
(40.2 ; 45.9)\end{array}$ & $\begin{array}{c}38.3 \\
(35.6 ; 41.0)\end{array}$ & $\begin{array}{c}39.0 \\
(36.9 ; 41.1)\end{array}$ \\
\hline Weight (kg) & $\begin{array}{c}71.9 \\
(69.2 ; 74.7)\end{array}$ & $\begin{array}{c}69.2 \\
(66.2 ; 72.3)\end{array}$ & $\begin{array}{c}71.8 \\
(68.4 ; 75.1)\end{array}$ \\
\hline Height $(\mathrm{cm})$ & $\begin{array}{c}167.7 \\
(166 ; 169.4)\end{array}$ & $\begin{array}{c}167.2 \\
(165.4 ; 169)\end{array}$ & $\begin{array}{c}168.8 \\
(167.2 ; 170.4)\end{array}$ \\
\hline $\begin{array}{l}\text { Number of akathisia } \\
\text { (score } \geq 2)(\%)\end{array}$ & $1(2.0 \%)$ & $3(4.2 \%)$ & 1 (1.4\%) \\
\hline $\begin{array}{l}\text { Marked or severe } \\
\text { akathisia (score } \geq 4 \text { ) }\end{array}$ & 0 & 1 & 0 \\
\hline
\end{tabular}

Table 1. Characteristics of population, incidence of akathisa and number of severe akathisia according to the Barnes rating scale. Results are expressed as mean or rate and $95 \%$ credibility intervals

\section{Conclusion}

Albeit rare, akathisia may be more frequent after droperidol prophylaxis when compared with ondanstron prophylaxis for PONV. The use of $1.25 \mathrm{mg}$ of droperidol can lead to marked akathisia. Better knowledge of the clinical features of akathisia and its objective assessment will allow the anaesthesists to better take this side effect into account.

References

1.Schaub I, Lysakowski C, Elia N, et al. Eur. J. Anaesthesiol. 2012;29:286-294

2.Barnes, TR. Br. J. Psychiatry J. Ment. Sci. 1989;154:672-676

3.Timbolschi D, Schaeffer, P. Vidailhet, P. Anesth Analg. 2009;108: S-15 